\title{
Octreotide inhibits the proliferation of gastric cancer cells through P300-HAT activity and the interaction of ZAC and P300
}

\author{
LIPING WANG $^{1}$, XIN HUANG $^{1}$, YURONG CHAI $^{1}$, LIYANG ZOU $^{1}$, MATTHEW CHEDRAWE $^{2}$ and YI DING $^{1}$ \\ ${ }^{1}$ Department of Histology and Embryology, College of Basic Medical Sciences, Zhengzhou University, \\ Zhengzhou, Henan 450001, P.R. China; ${ }^{2}$ Department of Psychology and Neuroscience, \\ Faculty of Science, Dalhousie University, Halifax, Nova Scotia B3H 4R2, Canada
}

Received June 17, 2016; Accepted July 28, 2016

DOI: $10.3892 /$ or.2017.5451

\begin{abstract}
Somatostatin (SST) exhibits a wide range of physiological functions, including the regulation of tumor cell growth. Octreotide (OCT) is a synthetic analogue of SST that can be used to slow gastrointestinal bleeding, inhibit the release of growth hormone and impede gastrointestinal tumor growth. The aim of the present study was to investigate the molecular mechanism of OCT underlying the inhibition of gastric cancer cell proliferation. Proteins of interest were detected using western blotting, and the zinc finger protein (ZAC)-P300 complex was quantified using co-immunoprecipitation. P300-histone acetyltransferase (P300-HAT) activity was determined spectrophotometrically. The results showed that OCT decreased the phosphorylation of Akt which caused the level of ZAC to increase. In turn, the interaction between ZAC and P300 increased the activity of P300-HAT; ultimately, the phosphorylation of serine 10 in histone $\mathrm{H} 3$ ( $\mathrm{pS10}-\mathrm{H} 3)$ was decreased and the acetylation of lysine 14 in histone H3 (acK14-H3) was increased. These results suggest that OCT attenuates SGC-7901 cell proliferation by enhancing P300-HAT activity through the interaction of ZAC and P300, causing a reduction in pS10-H3 and an increase in acK14-H3. These findings provide insight for future research on OCT and further demonstrate the potential of OCT to be used as a therapeutic agent for gastric cancer.
\end{abstract}

\section{Introduction}

Numerous post-translational modifications (PTMs) exist to further specify protein function; some examples include histone phosphorylation, acetylation, methylation and

Correspondence to: Yi Ding or Yurong Chai, Department of Histology and Embryology, College of Basic Medical Sciences, Zhengzhou University, 100 Kexue Road, Zhengzhou, Henan 450001, P.R. China

E-mail: dingyi@zzu.edu.cn

E-mail: yrchai@zzu.edu.cn

Key words: octreotide, gastric cancer, ZAC, P300, HAT, SGC-7901 ubiquitination (1). Histone PTMs are the points of convergence in signaling pathways and these nodal events are crucial for gene expression (2). Different histone PTMs have three major distinct outcomes. Firstly, cooperative interactions: two or more signals collaborate to promote protein stabilization or recruitment. Secondly, mutually exclusive PTMs: PTMs can be mutually exclusive, however, these different PTMs cannot occur simultaneously. Thirdly, antagonistic PTMs: a PTM that is attached to one amino acid can, for example, antagonize the ability of an adjacent modified residue to recruit a binding partner (3). Histone H3 is a substrate of signal kinase and its phosphorylation specificity involves cell cycle progression and gene expression regulation (4). An increasing number of histone modifying complexes are found to have more than one distinct enzymatic activity. These enzymes can act in concert to determine the functional status of chromatin by coordinating multiple histone modifications. It is now well established that there is intense crosstalk between histone modifications to drive distinct downstream functions as well. Cross-regulation can occur in different ways; one modification can promote/block the addition of another modification, while another modification can stimulate/block the removal of another (5).

Akt plays an important role in the growth factor signaling pathway and can regulate cell growth, transcription and nutrition metabolism (6). If the Akt signaling pathway is inhibited, it may therefore lead to tumor cell death and growth inhibition (7). Zinc finger proteins (ZACs) are transcription factors that have transactivation and DNA-binding functions which can induce apoptosis and cell cycle arrest (8). P300 is a transcription cofactor with histone acetyltransferase (HAT) activity which is capable of acetylating all four core histones as well as over 70 other proteins. Its histone HAT domain is the core domain by which it acetylates substrate proteins and promotes transcription (9-11). ZAC also acts as a transcriptional cofactor that works with HATs and histone deacetylases to regulate gene expression. Previous research has shown that the $Z A C$ gene exhibits hypermethylation in gastric adenocarcinomas (12).

When somatostatin (SST) binds to the SST receptor (SSTR) it can regulate cell proliferation in normal tissues and tumors. The SSTR is a G protein-coupled receptor and Akt is one of the downstream molecules in the SSTR pathway $(13,14)$. In 
gastric carcinomas, the expression of SST and ZAC are both downregulated implying that a positive correlation between SST and ZAC expression exists (15). Octreotide (OCT), an SST analogue, is able to upregulate the expression of the ZAC gene and inhibit the proliferation of gastric cancer cells (16). The inhibitory effect of OCT on the proliferation of gastric cancer cells was significantly reduced after siRNA knockdown of the ZAC gene. This suggests that ZAC plays an important role in OCT signaling to inhibit the proliferation of gastric cancer cells (16).

Simultaneous induction of histone phosphorylation and acetylation is crucial for the activation of specific mammalian genes. For instance, the phosphorylation and acetylation of histone $\mathrm{H} 3$ can influence the regulation of cell proliferation gene expression (17). Histone H3 serine residue phosphorylation is a highly dynamic process and the phosphorylation of serine 10 on histone $\mathrm{H} 3(\mathrm{pS} 10-\mathrm{H} 3)$ plays a significant role in the NF- $\kappa \mathrm{B}$ pathway of gene transactivation (18). S10-H3 phosphorylation is closely related to the acetylation of lysine 14 on histone H3 (acK14-H3) and acK9-H3 (19); in fact, pS10-H3 has been shown to stimulate acK14-H3 via GCN5, a proto-

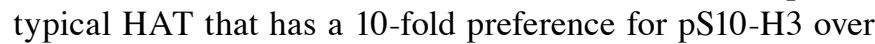
non-phosphorylated $\mathrm{H} 3$ as a substrate in vitro (20-22).

Although effort has been made to elucidate how OCT works, the exact mechanism is yet to be determined. The purpose of the present study was to determine the inhibitory mechanism of OCT in gastric cancer cells. More specifically, OCT was proposed to increase the activity of P300-histone acetyltransferase (P300-HAT) in gastric cancer cells by downregulating p-Akt and upregulating ZAC. We anticipated that acK14-H3 and pS10-H3 are target sites of $\mathrm{P} 300$; therefore, OCT may be able to regulate $\mathrm{pS10-H3}$ and acK14-H3 to inhibit gastric cancer cell proliferation.

\section{Materials and methods}

Cell culture. A human gastric carcinoma cell line (SGC-7901) was provided by the Cell Bank of the Chinese Academy of Sciences (Shanghai, China), and routinely cultured in RPMI-1640 medium (Gibco, Grand Island, NY, USA). The medium was supplemented with $10 \%$ fetal bovine serum, $100 \mathrm{U} / \mathrm{ml}$ penicillin and $100 \mu \mathrm{g} / \mathrm{ml}$ streptomycin (both from Sigma-Aldrich, St. Louis, MO, USA) at $37^{\circ} \mathrm{C}$ in a humidified atmosphere of $5 \% \mathrm{CO}_{2}$. OCT, which was used to treat cells, was obtained from Beijing Dingguo Co. (Beijing, China) formulated as OCT acetate injection.

Cell proliferation assay. Cell proliferation was assessed using a 3-(4,5-dimethylthiazol-2-yl)-2,5-diphenyltetrazolium bromide (MTT) viability assay. Briefly, cells $\left(5 \times 10^{3}\right.$ cells/well) were plated in 96 -well plates. The cells were treated with different concentrations of $\mathrm{OCT}(0,1,10,100$ and $1,000 \mathrm{nmol} / \mathrm{l})$ for $24 \mathrm{~h}$. At the end of each treatment, $10 \mu \mathrm{l}$ of MTT stock solution $(5 \mathrm{mg} / \mathrm{ml})$ was then added to each well, and the cells were incubated for an additional $4 \mathrm{~h}$. The blue formazan salts produced from the cells were dissolved by adding $100 \mu \mathrm{l}$ of dimethyl sulfoxide (DMSO) and the absorbance of the blue solution at $490 \mathrm{~nm}$ was measured using a Microplate Reader Model 550 (Bio-Rad, Hercules, CA, USA). The cytotoxicity of OCT was determined by plotting the inhibitory efficiency: IE\% $=[1$ - (optical density of sample/optical density of control)] x $100 \%$.

Western blot analysis. The SGC-7901 cells that underwent different treatments (10 nmol/1 of OCT treatment for 12, 24 and $48 \mathrm{~h}$, or no OCT) were collected after various time periods. Cells were then washed with cold phosphate-buffered saline (PBS) and lysed in ice-cold lysis buffer $(10 \mathrm{mmol} / 1 \mathrm{Tris}-\mathrm{HC} 1$, $\mathrm{pH}$ 8.0, 20\% SDS, $1 \mathrm{mmol} / 1$ EDTA, $5 \mathrm{mmol} / 1 \mathrm{DTT}, 10 \mathrm{mmol} / 1$ PMSF) for $30 \mathrm{~min}$ at $4^{\circ} \mathrm{C}$. Cell lysates were centrifuged at $13,400 \mathrm{x}$ g for $10 \mathrm{~min}$ at $4^{\circ} \mathrm{C}$ and protein concentrations in the supernatants were determined using a bicinchoninic acid (BCA) protein assay (BCA assay kit; Beyotime Institute of Biotechnology, Haimen, China) according to the manufacturer's instructions. A total of $100 \mathrm{mg}$ of protein was separated by $15 \%$ SDS-polyacrylamide gel electrophoresis (PAGE). After electrophoresis, gels were transferred to nitrocellulose/polyvinylidene fluoride (PVDF) membranes by electroblotting. The membranes were blocked with $5 \%$ non-fat dry milk in TBST (20 mmol/l Tris-HCl, pH 7.6, 137 mmol/l NaCl, 0.05\% Tween-20) for $2 \mathrm{~h}$ at room temperature and incubated with primary antibodies (1:500) against Akt, p-Akt, ZAC, P300, pS10-H3 and acK14-H3 (Santa Cruz Biotechnology, Inc., Santa Cruz, USA), and total $\beta$-actin overnight at $4^{\circ} \mathrm{C}$. After being washed three times for $20 \mathrm{~min}$ in TBST, the membranes were incubated for $1.5 \mathrm{~h}$ at room temperature with an appropriately diluted horseradish peroxidase-labeled secondary antibody (1:2,000; Zhongshan Jinqiao Beijing Biotechnology Co., Ltd., Beijing, China) in blotting buffer. The membranes underwent three 30-min washes in TBST with gentle shaking. The Akt, p-Akt, ZAC, P300, pS10-H3, acK14-H3 and total $\beta$-actin protein bands were visualized using the enhanced chemiluminescence (ECL) method. All proteins of interest were run alongside a housekeeping gene $(\beta$-actin, $1: 1,000)$. The relative level of protein in the SGC-7901 cells was expressed as the gray value/ $\beta$-tubulin.

Spectrophotometric activity. SGC-7901 cells received either $10 \mathrm{nmol} / \mathrm{l}$ of OCT treatment for 12, 24 and $48 \mathrm{~h}$ (experimental group), or no OCT treatment (control group). The nuclear proteins from all cells were extracted using the Nc-cell nucleus/plasma extraction kit (Beijing Dingguo Co.). The sample total activity and sample non-specific activity assays were performed using the kit following the manufacturer's instructions. The sample total activity and sample non-specific activity were evaluated via a UV-9000 spectrophotometer (Shanghai Yuanxi Instrument Co., Ltd., Shanghai, China).

The sample activity was calculated with the following equation:

$$
\frac{[(\mathrm{SR}-\mathrm{BR}) \times 0.1(\mathrm{SC}: \mathrm{ml}) \mathrm{SDM}]}{[0.01(\mathrm{SV}: \mathrm{ml}) \times 13.6(\mathrm{MAC} \times 15(\mathrm{~min}))]}=\frac{\text { unit } / \mathrm{ml}}{\mathrm{SPC}(\mathrm{mg} / \mathrm{ml})}=\text { unit } / \mathrm{mg}
$$

Here, SR signifies the sample reading, BR the background reading, SC the system capacity, SDM the sample dilution multiple, SV the sample volume, MAC the molar absorption coefficient and SPC the sample protein concentration. Unit $=\mathrm{mMol}$ Con $\mathrm{A} / \mathrm{min}$.

Sample specific activity $=$ sample total activity - sample non-specific activity 
Co-immunoprecipitation assays. Total proteins were extracted using the Nc-cell nucleus/plasma extraction kit obtained from Beijing Dingguo Co., and protein concentrations were determined using a BCA assay. The supernatant was then collected and incubated with an immunoprecipitating antibody [2 $\mathrm{g}$ (100 $\mu$ l) P300 antibody; Santa Cruz Biotechnology, Inc.] overnight at $4^{\circ} \mathrm{C}$ on a rotating wheel. Then, $40 \mu 1$ protein $\mathrm{A}$ agarose (Beijing Dingguo Co.) was added and incubation was carried out at $4^{\circ} \mathrm{C}$ overnight on a rotating wheel. Samples were then washed five times with lysis buffer and the final pellets were resuspended in $25 \mu \mathrm{l}$ of loading buffer $(100 \mathrm{mmol} / \mathrm{l}$ Tris- $\mathrm{HCl}, \mathrm{pH}$ 6.8, $200 \mathrm{mmol} / 1$ dithiothreitol, 4\% SDS, $0.2 \%$ bromophenol blue, $20 \%$ glycerol, $8 \%$ urea). Protein complexes were examined by western blotting with anti-ZAC (1:800; Santa Cruz Biotechnology, Inc.) to detect P300-ZAC interactions. Semi-quantitative analysis was carried out using ImageJ software and the band density indicated the relative amount of the P300-ZAC complex.

Immunocytochemistry. Immunocytochemistry was performed on slides with SGC-7901 cells after treatment with $10 \mathrm{nmol} / 1$ OCT for 12, 24 and $48 \mathrm{~h}$ and on those without OCT treatment. The slides were rinsed three times with $0.01 \mathrm{M}$ PBS, fixed with $4 \%$ paraformaldehyde, incubated with $0.3 \%$ Triton $\mathrm{X}-100$ in PBS for $1 \mathrm{~h}$ at room temperature, and placed in $1 \% \mathrm{H}_{2} \mathrm{O}_{2}$ in PBS for $30 \mathrm{~min}$ to quench endogenous peroxidases. The slides were then blocked with $5 \%$ bovine serum albumin (BSA) and incubated with primary polyclonal antibody [anti-pS10-H3 (1:200); anti-acK14-H3 (1:100); Santa Cruz Biotechnology, Inc.], and after washes with PBS a secondary antibody [biotinylated goat anti-rabbit (1:500)] was added. Next, the slides were incubated with a strepavidin-biotin complex (SABC) and processed with 3,3'-diaminobenzidine solution. A $0.1 \%$ methyl green staining solution was used to stain the cell nuclei.

All cells were scored based on immunoreactivity (IR) under a microscope. Cells with no IR were considered negative ( 0 points); cells with light brown granules were considered weakly positive (1 point); cells that had brown granules were considered positive (2 points).

Statistical analysis. The Student's t-test and one-way ANOVA were used to statistically analyze the data using SPSS 20.0 statistical software. The data from triplicate experiments are expressed as the mean \pm SD and a $\mathrm{p}<0.05$ was considered to indicate a statistically significant result.

\section{Results}

In vitro anticancer effects of OCT. SGC-7901 cells were incubated with increasing concentrations of OCT for $24 \mathrm{~h}$ and the viability was evaluated by MTT assay (Fig. 1). Four different concentrations of OCT $(1,10,100$ and 1,000 nmol/l) inhibited the growth of SGC-7901 cells to varying extents. Considering that the efficiency of inhibition for 10 and $100 \mathrm{nmol} / 1$ were comparable, $10 \mathrm{nmol} / \mathrm{l}$ of OCT was chosen as the effective concentration for the present study.

OCT decreases $p$-Akt levels and increases ZAC expression. SGC-7901 cells were treated with $10 \mathrm{nmol} / 1$ of OCT for $24 \mathrm{~h}$. Compared to the control group, no significant change in the

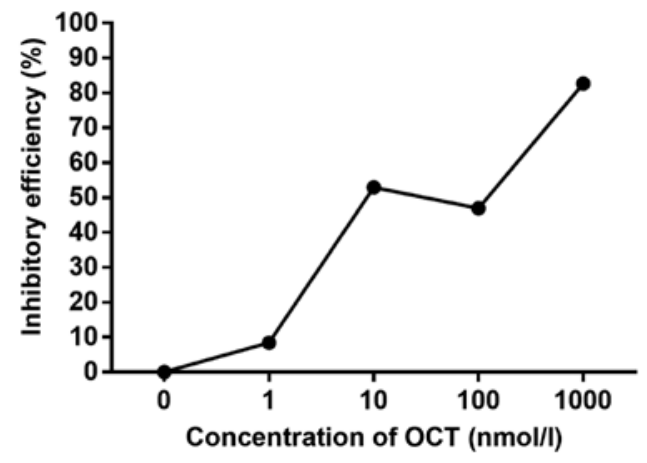

Figure 1. Inhibitory efficiency of SGC-7901 cells is determined at different concentrations of OCT using an MTT viability assay; 10 and $100 \mathrm{nmol} / \mathrm{l}$ OCT inhibited SGC-7901 cell growth to a similar extent, thus, $10 \mathrm{nmol} / 1$ was chosen as the representative concentration.
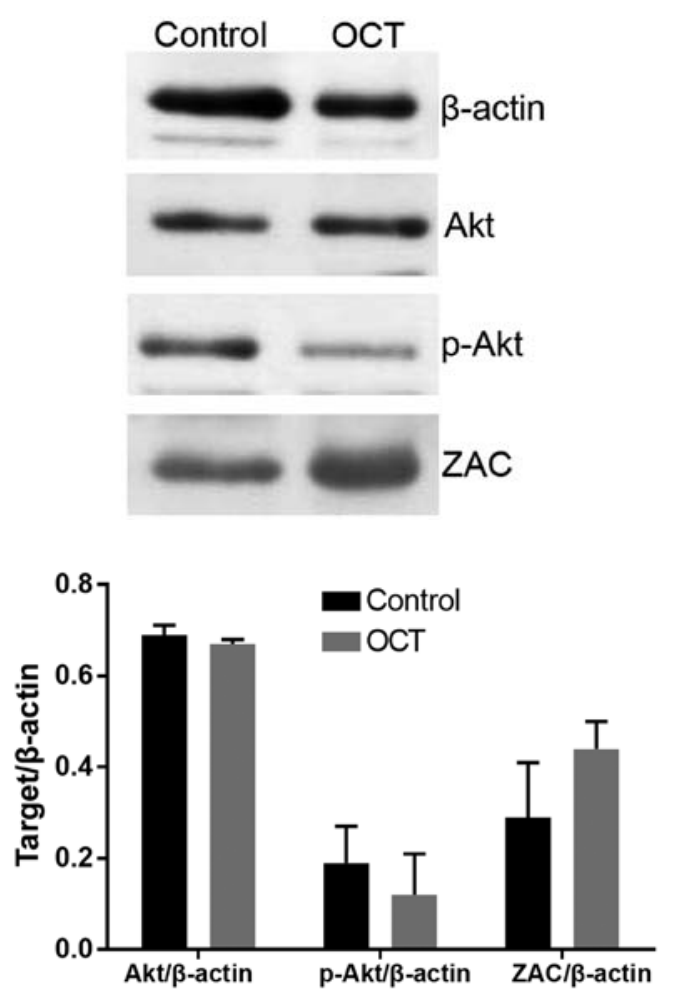

Figure 2. Effect of $10 \mathrm{nmol} / 1$ of OCT at $24 \mathrm{~h}$ on the expression levels of Akt, p-Akt and ZAC in SGC-7901 cells. There was no change in the expression of the Akt protein when compared to the control groups, although there was a decrease in the p-Akt level in the OCT-treated cells compared to the level in the control group. The expression of the ZAC protein in the OCT-treated cells was significantly increased when compared to the level in the control group $(\mathrm{p}<0.05)$

expression of Akt was detected ( $p>0.05)$; however, the level of $\mathrm{p}$-Akt was significantly decreased $(\mathrm{p}<0.05)$. In addition, the expression of ZAC was significantly increased in the OCT-treated cells when compared to that noted in the control group ( $\mathrm{p}<0.05$; Fig. 2). Overall, Akt levels were not affected by OCT, yet OCT decreased the amount of p-Akt and increased the levels of ZAC in the SGC-7901 cells.

OCT increases P300-HAT activity in the gastric cancer cells. The P300-HAT activity in the nucleoprotein of SGC-7901 cells was detected spectrophotometrically after incubation 


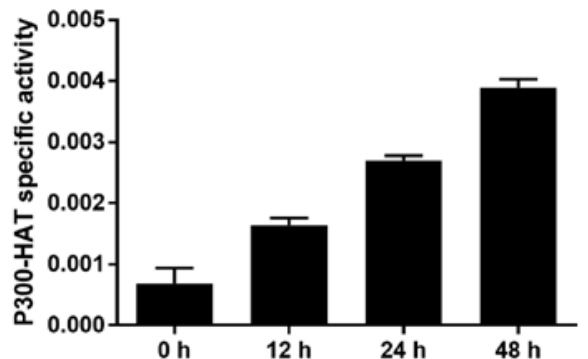

Figure 3. Spectrophotometric method was applied to detect the specific activity of P300-HAT in the SGC7901 cells treated with $10 \mathrm{nmol} / 1 \mathrm{OCT}$. OCT increased P300-HAT activity in a time-dependent manner $(\mathrm{p}<0.05)$.
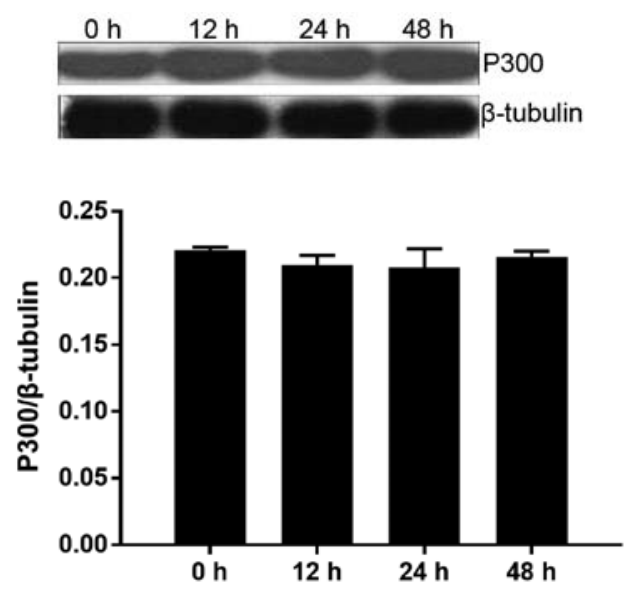

Figure 4. $P 300$ gene expression in $10 \mathrm{nmol} / \mathrm{l}$ OCT-treated cells remained constant at all time-points $(\mathrm{p}>0.05)$.
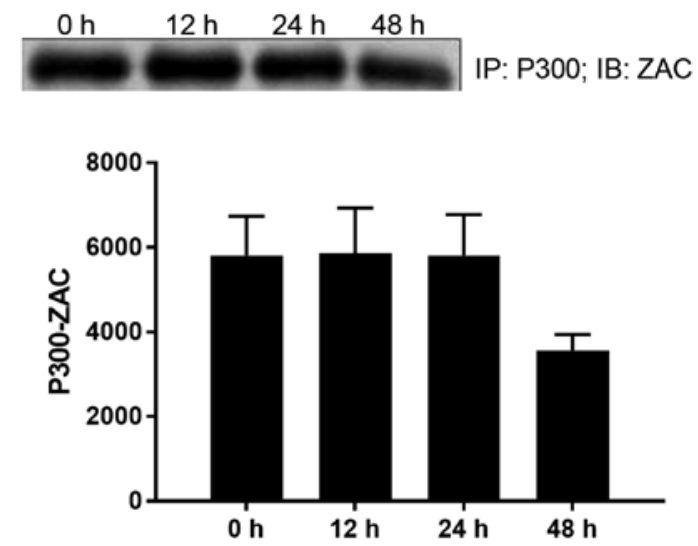

Figure 5. Interaction between ZAC and P300 in SGC-7901 cells. The amount of the ZAC-P300 complex did not change in the $10 \mathrm{nmol} / 1$ OCT-treated SGC-7901 cells at 0,12 and $24 \mathrm{~h}(\mathrm{p}>0.05)$; however, it decreased when treated with OCT for $48 \mathrm{~h}(\mathrm{p}<0.05)$.

with OCT for 12,24 and $48 \mathrm{~h}$. OCT (10 nmol/l) significantly enhanced P300-HAT activity in the SGC-7901 cells in a time-dependent manner $(\mathrm{p}<0.05$; Fig. 3$)$. This outcome revealed that OCT increased the overall activity of P300-HAT in the SGC-7901 cells.

OCT does not alter P300 gene expression in the gastric cancer cells. To observe the effects of OCT on $P 300$ gene expression, the amount of P300 in SGC-7901 cells was determined using

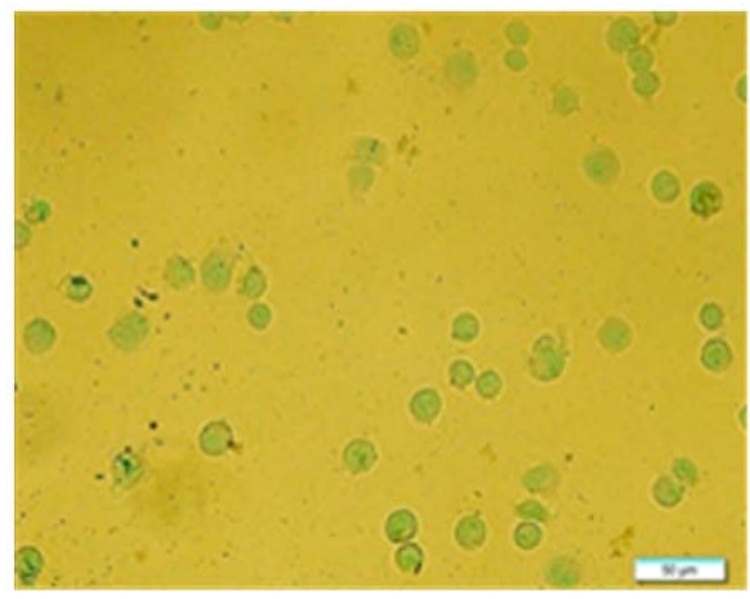

Figure 6. Representative micrograph of the appearance of pS10-H3 IR after $12 \mathrm{~h}$ of $10 \mathrm{nmol} / 1$ of OCT treatment. The pS10-H3 IR appeared as brown granules and was mainly distributed in the periphery of the nucleus.

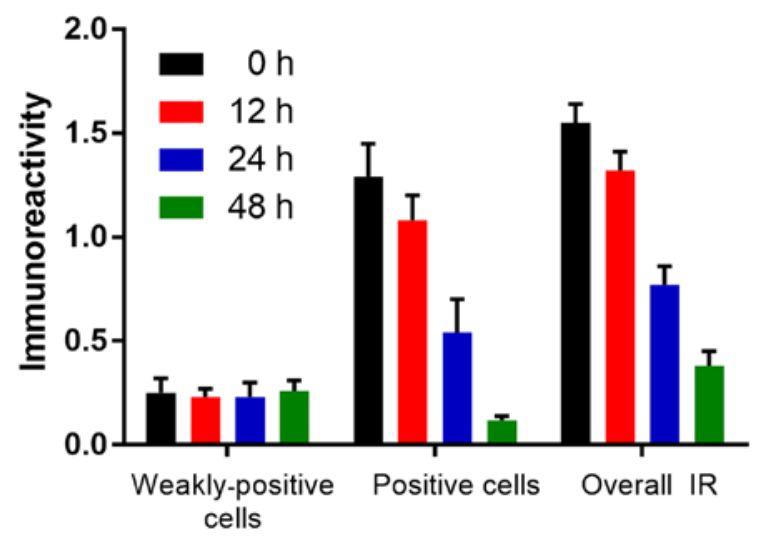

Figure 7. Effect of OCT on pS10-H3 IR in the SGC-7901 cells. There was no difference between the average pS10-H3 IR across all weakly positive cell conditions. The averages of pS10-H3 IR for positive cells were decreased in a time-dependent manner.

western blotting. There was no significant difference in $P 300$ gene expression between the control and the experimental groups when SGC-7901 cells were incubated with OCT for 12, 24 and $48 \mathrm{~h}$ (p>0.05; Fig. 4). This result demonstrated that the $P 300$ gene expression was not altered by OCT treatment in the SGC-7901 cells.

Interaction between ZAC and P300 in the gastric cancer cells. The co-immunoprecipitation assay showed that ZAC interacted with P300 in the SGC7901 cells. There was no significant difference in the amount of ZAC-P300 complex after 12 and $24 \mathrm{~h}$ of treatment with $10 \mathrm{nmol} / \mathrm{l}$ of OCT when compared to the control group ( $>0.05$ ); however, the amount of ZAC-P300 at $48 \mathrm{~h}$ was significantly decreased $(\mathrm{p}<0.05$; Fig. 5). Overall, the interaction between $\mathrm{ZAC}$ and $\mathrm{P} 300$ remained constant in the SGC-7901 cells without OCT treatment and in those treated with $10 \mathrm{nmol} / \mathrm{l}$ of OCT for 12 and $24 \mathrm{~h}$.

OCT decreases pS10-H3 IR in positive gastric cancer cells. The IR of pS10-H3 in SGC-7901 cells was determined using immunocytochemistry. pS10-H3 IR appeared as brown 

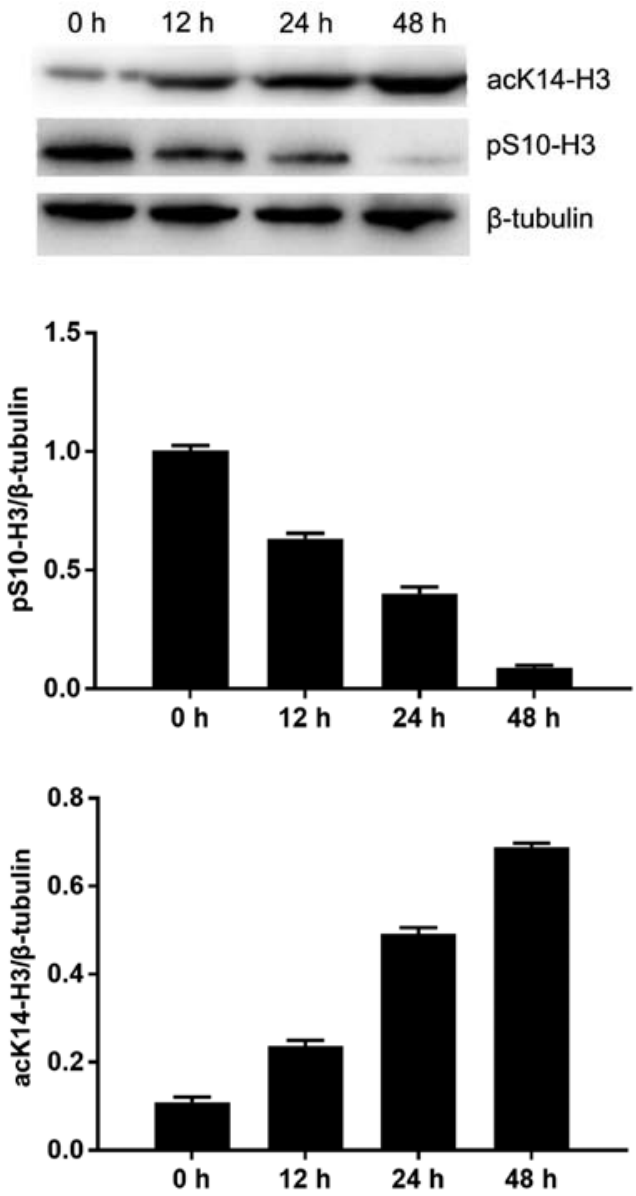

Figure 8. OCT $(10 \mathrm{nmol} / \mathrm{l})$ decreased the level of $\mathrm{pS} 10-\mathrm{H} 3(\mathrm{p}<0.01)$ and increased the level of acK14-H3 $(\mathrm{p}<0.01)$ in the SGC-7901 cells in a timedependent manner.

granules and was mainly distributed in the periphery of the nucleus (Fig. 6). The average percentage of weakly positive and positive cells in each group was calculated. The average IR of pS10-H3-positive cells decreased in a time-dependent manner. However, there was no significant difference $(\mathrm{p}>0.05)$ in the average IR of weakly positive cells between the control and experimental groups (Fig. 7). Thus, OCT decreased pS10-H3 IR levels in the SGC-7901-positive cells.

OCT decreases the level of $p S 10-H 3$ in the gastric cancer cells. To determine the effect of OCT on pS10-H3, the amount of pS10-H3 in SGC-7901 cells was quantified using western blotting. The relative level of pS10-H3 was significantly decreased in a time-dependent manner in cells treated with $10 \mathrm{nmol} / \mathrm{l}$ of OCT $(\mathrm{p}<0.01)$. Therefore, OCT significantly decreased the level of pS10-H3 in the SGC-7901 cells (Fig. 8).

OCT increases acK14-H3 IR in gastric cancer cells. Similar to the pS10-H3 IR, the acK14-H3 IR appeared as brown granules and was mainly distributed in the periphery of the nucleus (Fig. 9). The average level of acK14-H3 IR for weakly positive and positive cells in the control group was significantly lower than that in the experimental groups $(\mathrm{p}<0.01$; Fig. 10). OCT was therefore able to significantly increase acK14-H3 IR in the SGC-7901 cells.

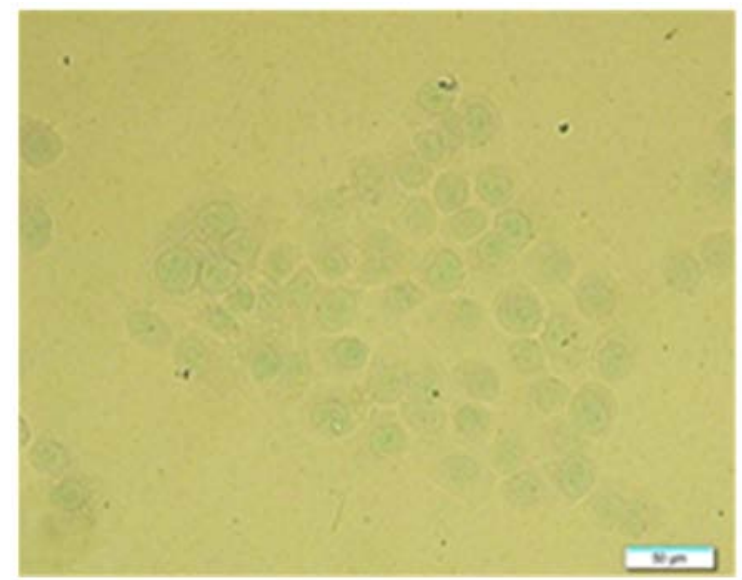

Figure 9. A representative micrograph of the appearance of acK14-H3 IR after $48 \mathrm{~h}$ of $10 \mathrm{nmol} / 1$ OCT treatment. acK14-H3 IR appeared as brown granules and was mainly distributed in the periphery of the nucleus.

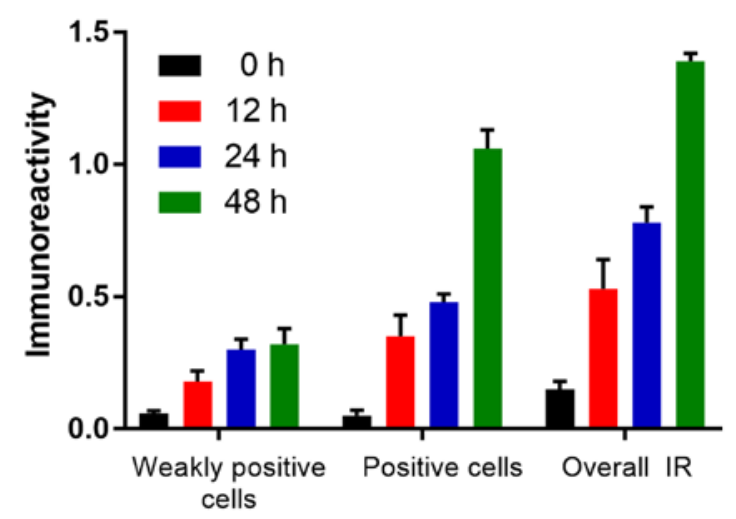

Figure 10. The average level of acK14-H3 IR in the weakly positive and positive cells in the control group was significantly lower than that in all OCT-treated groups $(\mathrm{p}<0.01)$.

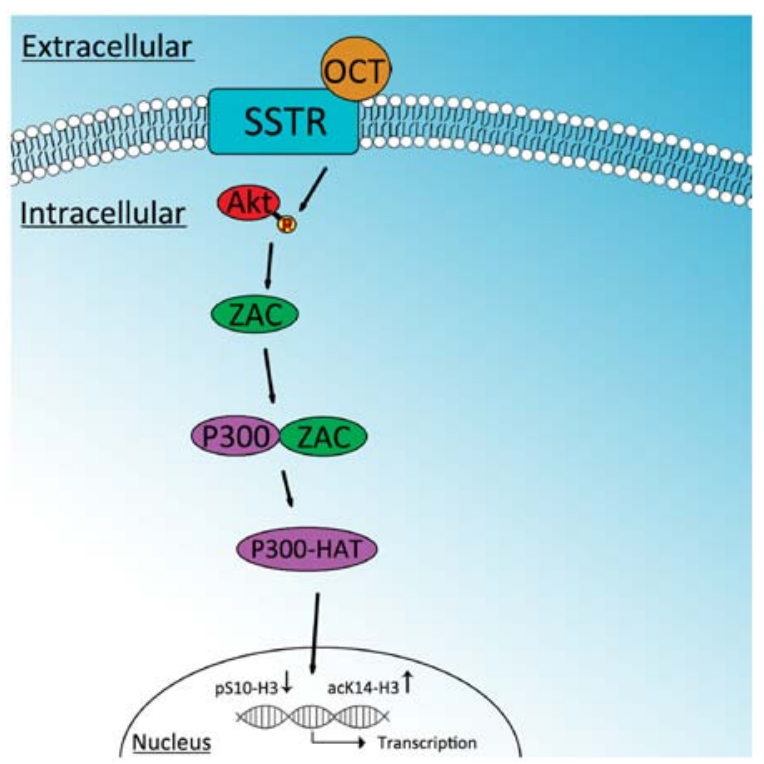

Figure 11. Proposed mechanism by which OCT acts to inhibit SGC-7901 cell proliferation. OCT binds to the SSTR to lower p-Akt and increase ZAC expression. ZAC interacts with P300 to increase P300-HAT activity which acts in the nucleus to decrease pS10-H3 (decreases the expression of proliferation-promoting genes) and increase acK14-H3 (increases the expression of proliferation-inhibiting genes). 
OCT increases the level of acK14-H3 in the gastric cancer cells. To determine the effect of OCT on acK14-H3, the amount of acK14-H3 in the SGC-7901 cells was determined using western blotting. The level of acK14-H3 was significantly increased in a time-dependent manner in cells treated with $10 \mathrm{nmol} / 1$ of OCT $(\mathrm{p}<0.01)$. OCT therefore significantly increased the level of acK14-H3 in the SGC-7901 cells (Fig. 8).

\section{Discussion}

The present study examined the mechanism of OCT in the inhibition of SGC-7901 cell proliferation. Since the inhibitory efficiency of 10 and $100 \mathrm{nmol} / \mathrm{l}$ of OCT were similar, $10 \mathrm{nmol} / \mathrm{l}$ of OCT was selected as the effective concentration (Fig. 1).

Gao et al suggested that Akt/PKB and telomerase activity in SGC-7901 cells was significantly inhibited when the cells were exposed to $1 \mu \mathrm{g} / \mathrm{ml}$ of OCT for 12,24 and $48 \mathrm{~h}$ compared to that of the control counterparts (23). The present study demonstrated that there was no difference in the level of Akt between the OCT-treated group and that of the control group in SGC-7901 cells. However, there was a decrease in the p-Akt level in the SGC-7901 cells treated with $10 \mathrm{nmol} / \mathrm{l}$ of OCT for $24 \mathrm{~h}$ compared to the control group (Fig. 2); this suggested that OCT inhibited Akt activity rather than Akt expression. This decrease in Akt activity may shift SSTR signaling from pro-survival to promoting the inhibition of SGC-7901 cell growth.

In pituitary tumor cells, OCT produces its antiproliferative action by acting on the PI3K/Akt signaling pathway and by increasing $Z A C 1$ gene expression (24). It has been previously shown that there is a positive correlation between the expression of ZAC and SST in gastric cancer tissue. Through the combination of SST and the SSTR3, ZAC expression was promoted and resulted in the inhibition of gastric tumor cell growth (15). Our present study revealed that OCT upregulated the expression of ZAC in SGC-7901 cells (Fig. 2) which supports the notion that OCT inhibits the proliferation of gastric cancer cells by reducing the level of Akt phosphorylation and upregulating ZAC expression.

Our research demonstrated that the P300-HAT activity in the SGC-7901 cells was increased in a time-dependent manner after being incubated with $10 \mathrm{nmol} / 1$ of OCT (Fig. 3); this indicated that OCT upregulated the activity of P300-HAT. The mechanism by which OCT upregulates P300-HAT activity in SGC-7901 cells is potentially multi-faceted. Firstly, OCT increases the activity of P300-HAT by upregulating the expression of P300 in SGC-7901 cells. Secondly, since OCT upregulates the expression of ZAC in SGC-7901 cells, ZAC and P300 proteins can interact to increase P300-HAT activity. Thirdly, increased P300 and ZAC have a synergistic action on the activity of P300-HAT. Our results revealed that there was no difference in the $P 300$ gene expression between the control and the experimental groups (Fig. 4), therefore, the first and the third hypotheses can be excluded. In light of this, we applied co-immunoprecipitation to observe the interaction of ZAC and P300 protein in SGC-7901 cells.

Coordinated binding of $\mathrm{ZAC}$ zinc fingers and $\mathrm{C}$ terminus to P300 regulates HAT function by increasing histone and acetyl coenzyme A affinities and catalytic activity. This concerted regulation of HAT function is mediated via the KIX and
$\mathrm{CH} 3$ domains of P300 in an interdependent manner. Notably, ZAC zinc fingers 6 and 7 simultaneously play key roles in DNA binding and P300 regulation (25). We suggested that P300-ZAC was present in the control and experimental groups by way of co-immunoprecipitation within SGC-7901 cells. Notably, there was no significant difference in the amount of P300-ZAC between the control and the 12 and 24-h groups. However, the amount of P300-ZAC in the 48-h group was significantly less than that in the other three groups (Fig. 5).

There are many potential reasons as to why the amount of P300-ZAC decreased at $48 \mathrm{~h}$ of OCT treatment. ZAC regulates the activities of the nuclear receptor, different members of the p53 family and all of the proteins that are crucial regulatory factors for cell growth, differentiation, equilibrium and development (26). The formation of a complex between P300 and p53 can, in turn, activate p53 (27,28). The activity of P300-HAT was found to be significantly increased when it interacted with special transcription factors (29). P300/CBP not only catalyzes the acetylation of all of the four core histones, but it also acetylates 70 other proteins and itself (10). Therefore, we speculated that OCT would upregulate the expression of the $Z A C$ gene in SGC-7901 cells and that the interaction of ZAC and P300 not only would upregulate the activity of P300-HAT, but also influence the expression and activity of other transcription factors which can competitively inhibit the formation of ZAC-P300. This may thereby create a negative feedback loop, causing the amount of ZAC-P300 in SGC-7901 cells to decrease after OCT treatment for $48 \mathrm{~h}$. However, the combination of these transcription factors and P300 may also increase the activity of P300-HAT, which can explain why ZAC plays a key role in inhibiting the pathway of gastric cancer cell proliferation. Our previous research demonstrated that $10 \mathrm{nmol} / \mathrm{l}$ of OCT, in the time period of 12-48 h, induced the expression of the ZAC gene in a time-dependent manner in gastric cancer cells (16). The result of the present study also showed that, in the time perios of 12-48 h, $10 \mathrm{nmol} / 1$ of OCT increased the activity of P300-HAT in the gastric cancer cells in a timedependent manner (Fig. 3). Since OCT upregulates the activity of P300-HAT, it most likely affects the histone acetylation of ZAC and other tumor-suppressor gene promoters in SGC-7901 cells. ZAC may then affect histone acetylation of other tumorsuppressor gene promoters by the upregulation of P300-HAT activity, in addition to inducing apoptosis and cell cycle arrest. The increased expression of these genes may likely inhibit the proliferation of SGC-7901 cells.

Since tumor cells are heterogeneous, we observed the effect of OCT on pS10-H3 IR in SGC-7901 cells using an immunocytochemistry method. The levels of pS10-H3 IR in each cell were not uniform which indicates the functional status of heterogeneity in SGC-7901 cells. The results showed that $\mathrm{pS} 10-\mathrm{H} 3 \mathrm{IR}$ was mainly distributed in the periphery of the nucleus (Fig. 6), which may relate to the translocation of p-Akt from the cytoplasm to the nucleus. Our results revealed that the average IR of pS10-H3-positive cells was decreased compared to that of the control group, however, there was no significant difference between all groups for the average IR of weakly positive $\mathrm{pS} 10-\mathrm{H} 3$ cells (Fig. 7). This indicates that OCT mainly decreased the expression of highly active proliferationpromoting genes (positive cells). There was, however, little effect on proliferation-inhibiting genes that were being subtly 
expressed (weakly positive cells) which further describes the heterogeneity of pS10-H3 expression in SGC-7901 cells.

In mammalian cells, pS10-H3 effects and causes stress of the stimulation of certain genes, such as c-fos and c-jun, via the mitogen stimulation signaling pathway $(30,31)$. Our current results showed that OCT significantly decreased pS10-H3 (Fig. 8), which indicates that it may downregulate the mitogen stimulation signaling pathway. The expression of some proliferation-promoting genes may therefore be decreased by the observed decrease in pS10-H3.

Acetylated DNA is usually labeled as active chromatin. Lieberman-Aiden et al showed that the genome is divided into open (active) and closed (inert) states (32). The present study, revealed that acK14-H3 IR was mainly distributed in the periphery of the nucleus (Fig. 9) which seems contrary to the view of inert chromatin being distributed in the periphery of the nucleus (33). However, it has been shown that epigenetic modification can occur in chromatin located in the peripheral area of the nucleus in tumor cells to alter the three-dimensional structure of chromatin, rendering it active $(34,35)$. The abrogation of the ability of the tumor cells to alter between open and closed states of chromatin may be related to the finding that acK14-H3 IR was mainly distributed in the periphery of the nucleus. The level of acK14-H3 IR between weakly positive and positive cells was not uniform which indicated that the state of chromatin in the SGC-7901 cells could be both open or closed. Both acK14-H3 IR (Fig. 10) and acK14-H3 (Fig. 8) increased in a time-dependent manner in the SGC-7901 cells treated with $10 \mathrm{nmol} / \mathrm{l}$ of OCT. Moreover, the IR results indicated that OCT may increase acK14-H3 in cells with a high expression of proliferation-inhibiting genes (positive cells), and have a smaller effect in cells with a low expression of proliferation-promoting genes (weakly positive cells), thereby inhibiting the growth of SGC-7901 cells.

All the results indicate that OCT may affect $\mathrm{pS} 10-\mathrm{H} 3$ and acK14-H3 in SGC-7901 cells to balance the expression of genes involved in proliferation and inhibition. OCT can significantly decrease pS10-H3 and significantly increase acK14-H3, which appears to be contrary to the view of mutual promotion between $\mathrm{pS} 10-\mathrm{H} 3$ and acK14-H3. This may be due to the fact that histone modifications have a high degree of background dependence. Histone PTMs may play a role in a gene-signal-specificity manner and do not have a universal code, instead, they are annotated against various regulatory signals within the genome (36). The biological outcomes of certain PTMs are usually dependent on the modification of chromatin and the cell background (37). Histone PTMs behave with a less strict 'code' and more with a complex 'language', which better illustrates that it is more reliant on the importance of the context, rather than convention. Only the 'language' deciphered in a certain context can produce a specific functional outcome (38).

There are, however, some limitations to the double modification of $\mathrm{pS10}-\mathrm{H} 3$ and acK14-H3 as they may not be suitable for the expression of some genes. P300 is a cofactor of oncoproteins (such as fos, jun and myb) and transforming virus proteins (such as E1A), in addition to being a cofactor for tumor-suppressor proteins (such as p53, E2F, Rb or BRCA1 (39). By upregulating P300-HAT activity, OCT may also affect the expression of oncogenes in SGC-7901 cells. In addition, cancer cells express multiple SSTR subtypes which indicate that these receptors are coupled with other intracellular receptor systems and extracellular signal cascades (40). There is still a great deal of information on SSTR subtypes pertaining to their involvement in physiological functions and different kinase and phosphatase activities that are still not fully understood.

In conclusion, the present study demonstrated that OCT may inhibit the proliferation of SGC-7901 cells by decreasing p-Akt, which in turn, increases ZAC. ZAC then interacts with P300 to increase P300-HAT activity. This ultimately decreases pS10-H3 and increases acK14-H3. Therefore, a decrease in pS10-H3 and an increase in acK14-H3 may be involved in the antiproliferative effects of OCT in SGC-7901 cells (Fig. 11).

\section{Acknowledgements}

The present study was funded by the Department of Science and Technology of Henan Province (project no. 102102310111).

\section{References}

1. Proietto M, Bianchi MM, Ballario P and Brenna A: Epigenetic and posttranslational modifications in light signal transduction and the circadian clock in Neurospora crassa. Int J Mol Sci 16: 15347-15383, 2015.

2. Banerjee T and Chakravarti D: A peek into the complex realm of histone phosphorylation. Mol Cell Biol 31: 4858-4873, 2011.

3. Seet BT, Dikic I, Zhou MM and Pawson T: Reading protein modifications with interaction domains. Nat Rev Mol Cell Biol 7: 473-483, 2006.

4. Edmunds JW and Mahadevan LC: MAP kinases as structural adaptors and enzymatic activators in transcription complexes. $\mathrm{J}$ Cell Sci 117: 3715-3723, 2004.

5. Izzo A and Schneider R: Chatting histone modifications in mammals. Brief Funct Genomics 9: 429-443, 2010.

6. Brazil DP and Hemmings BA: Ten years of protein kinase B signalling: A hard Akt to follow. Trends Biochem Sci 26: 657-664, 2001 .

7. Tokunaga E, Oki E, Egashira A, Sadanaga N, Morita M, Kakeji Y and Maehara Y: Deregulation of the Akt pathway in human cancer. Curr Cancer Drug Targets 8: 27-36, 2008.

8. Varrault A, Ciani E, Apiou F, Bilanges B, Hoffmann A, Pantaloni C, Bockaert J, Spengler D and Journot L: $h Z A C$ encodes a zinc finger protein with antiproliferative properties and maps to a chromosomal region frequently lost in cancer. Proc Natl Acad Sci USA 95: 8835-8840, 1998.

9. Chen J and Li Q: Use of histone deacetylase inhibitors to examine the roles of bromodomain and histone acetylation in p300-dependent gene expression. Methods Mol Biol 977: 353-357, 2013.

10. Chen Lf, Fischle W, Verdin E and Greene WC: Duration of nuclear NF-kappaB action regulated by reversible acetylation. Science 293: 1653-1657, 2001.

11. Zhang X, Ouyang S, Kong X, Liang Z, Lu J, Zhu K, Zhao D, Zheng M, Jiang H, Liu X, et al: Catalytic mechanism of histone acetyltransferase p300: From the proton transfer to acetylation reaction. J Phys Chem B 118: 2009-2019, 2014.

12. Li Z, Ding Y, Zhu Y, Yin M, Le X, Wang L, Yang Y and Zhang Q: Both gene deletion and promoter hyper-methylation contribute to the down-regulation of ZAC/PLAGL1 gene in gastric adenocarcinomas: A case control study. Clin Res Hepatol Gastroenterol 38: 744-750, 2014.

13. Florio T: Molecular mechanisms of the antiproliferative activity of somatostatin receptors (SSTRs) in neuroendocrine tumors. Front Biosci 13: 822-840, 2008.

14. Gatto F and Hofland LJ: The role of somatostatin and dopamine $\mathrm{D}_{2}$ receptors in endocrine tumors. Endocr Relat Cancer 18: R233-R251, 2011.

15. Zhang GZDY, Liu J, Le XP and Zhang QX: Correlation of ZAC with somatostatin and its receptor expression in gastric cancer tissues. Acta Anat Sinica 39: 703-707, 2008. 
16. Dai W, Ding Y and Zhang QX: Role of ZAC gene in the pathway of octreotide inhibiting proliferation of gastric cancer cells in vitro. Acta Anat Sinica 44: 492-497, 2013.

17. Simboeck E, Sawicka A, Zupkovitz G, Senese S, Winter S, Dequiedt F, Ogris E, Di Croce L, Chiocca S and Seiser C: A phosphorylation switch regulates the transcriptional activation of cell cycle regulator $\mathrm{p} 21$ by histone deacetylase inhibitors. J Biol Chem 285: 41062-41073, 2010.

18. Winter S, Simboeck E, Fischle W, Zupkovitz G, Dohnal I, Mechtler K, Ammerer G and Seiser C: 14-3-3 proteins recognize a histone code at histone $\mathrm{H} 3$ and are required for transcriptional activation. EMBO J 27: 88-99, 2008.

19. Sawicka A and Seiser C: Histone H3 phosphorylation - a versatile chromatin modification for different occasions. Biochimie 94 2193-2201, 2012.

20. Cheung P, Tanner KG, Cheung WL, Sassone-Corsi P, Denu JM and Allis CD: Synergistic coupling of histone H3 phosphorylation and acetylation in response to epidermal growth factor stimulation. Mol Cell 5: 905-915, 2000.

21. Clements A, Poux AN, Lo WS, Pillus L, Berger SL and Marmorstein R: Structural basis for histone and phosphohistone binding by the GCN5 histone acetyltransferase. Mol Cell 12: 461-473, 2003.

22. Lo WS, Trievel RC, Rojas JR, Duggan L, Hsu JY, Allis CD, Marmorstein R and Berger SL: Phosphorylation of serine 10 in histone $\mathrm{H} 3$ is functionally linked in vitro and in vivo to Gcn5-mediated acetylation at lysine 14. Mol Cell 5: 917-926, 2000.

23. Gao S, Yu BP, Li Y, Dong WG and Luo HS: Antiproliferative effect of octreotide on gastric cancer cells mediated by inhibition of Akt/PKB and telomerase. World J Gastroenterol 9: 2362-2365, 2003.

24. Theodoropoulou M, Zhang J, Laupheimer S, Paez-Pereda M, Erneux C, Florio T, Pagotto U and Stalla GK: Octreotide, a somatostatin analogue, mediates its antiproliferative action in pituitary tumor cells by altering phosphatidylinositol 3-kinase signaling and inducing Zac1 expression. Cancer Res 66: 1576-1582, 2006.

25. Hoffmann A, Barz T and Spengler D: Multitasking $\mathrm{C}_{2} \mathrm{H}_{2}$ zinc fingers link Zac DNA binding to coordinated regulation of p300-histone acetyltransferase activity. Mol Cell Biol 26: 5544-5557, 2006.

26. Theodoropoulou M, Stalla GK and Spengler D: ZAC1 target genes and pituitary tumorigenesis. Mol Cell Endocrinol 326: 60-65, 2010.

27. Arora A, Gera S, Maheshwari T, Raghav D, Alam MJ, Singh RK and Agarwal SM: The dynamics of stress p53-Mdm2 network regulated by p300 and HDAC1. PLoS One 8: e52736, 2013.
28. Wang F, Marshall CB and Ikura M: Transcriptional/epigenetic regulator $\mathrm{CBP} / \mathrm{p} 300$ in tumorigenesis: Structural and functional versatility in target recognition. Cell Mol Life Sci 70: 3989-4008, 2013.

29. Soutoglou E, Viollet B, Vaxillaire M, Yaniv M, Pontoglio M and Talianidis I: Transcription factor-dependent regulation of $\mathrm{CBP}$ and P/CAF histone acetyltransferase activity. EMBO J 20: 1984-1992, 2001.

30. Dyson MH, Thomson S and Mahadevan LC: Heat shock, histone $\mathrm{H} 3$ phosphorylation and the cell cycle. Cell Cycle 4: 13-17, 2005.

31. Ray PD, Huang BW and Tsuji Y: Coordinated regulation of Nrf2 and histone $\mathrm{H} 3$ serine 10 phosphorylation in arsenite-activated transcription of the human heme oxygenase-1 gene. Biochim Biophys Acta 1849: 1277-1288, 2015.

32. Lieberman-Aiden E, van Berkum NL, Williams L, Imakaev M, Ragoczy T, Telling A, Amit I, Lajoie BR, Sabo PJ, Dorschner MO, et al: Comprehensive mapping of long-range interactions reveals folding principles of the human genome. Science 326: 289-293, 2009.

33. Andrulis ED, Neiman AM, Zappulla DC and Sternglanz R: Perinuclear localization of chromatin facilitates transcriptional silencing. Nature 394: 592-595, 1998.

34. Berman BP, Weisenberger DJ, Aman JF, Hinoue T, Ramjan Z, Liu Y, Noushmehr H, Lange CP, van Dijk CM, Tollenaar RA, et al: Regions of focal DNA hypermethylation and long-range hypomethylation in colorectal cancer coincide with nuclear lamina-associated domains. Nat Genet 44: 40-46, 2011.

35. Hansen KD, Timp W, Bravo HC, Sabunciyan S, Langmead B McDonald OG, Wen B, Wu H, Liu Y, Diep D, et al: Increased methylation variation in epigenetic domains across cancer types. Nat Genet 43: 768-775, 2011.

36. Paska AV and Hudler P: Aberrant methylation patterns in cancer: A clinical view. Biochem Med 25: 161-176, 2015.

37. Berger SL: The complex language of chromatin regulation during transcription. Nature 447: 407-412, 2007.

38. Oliver SS and Denu JM: Dynamic interplay between histone H3 modifications and protein interpreters: Emerging evidence for a 'histone language'. ChemBioChem 12: 299-307, 2011.

39. Winter S, Fischle W and Seiser C: Modulation of 14-3-3 interaction with phosphorylated histone $\mathrm{H} 3$ by combinatorial modification patterns. Cell Cycle 7: 1336-1342, 2008.

40. Ferjoux G, Bousquet C, Cordelier P, Benali N, Lopez F, Rochaix P, Buscail L and Susini C: Signal transduction of somatostatin receptors negatively controlling cell proliferation. J Physiol Paris 94: 205-210, 2000. 